\title{
NOTAS INICIAIS SOBRE A COMPATIBILIDADE ENTRE PROTEÇÃO SOCIAL E AMBIENTAL E O COMPLEXO PORTUÁRIO DO AÇU NO NORTE FLUMINENSE
}

\author{
INITIAL REMARKS ON THE COMPATIBILITY BETWEEN SOCIAL AND ENVIRONMENTAL \\ PROTECTION AND THE AÇU PORT COMPLEX IN THE NORTHERN OF RIO DE JANEIRO STATE
}

Resumo: O Complexo Logístico Industrial e Portuário do Açu (CLIPA) está localizado no $5^{\circ}$ Distrito de São João da Barra, um território habitado por comunidades agrícola e pesqueira afetadas pelos impactos do CLIPA e alvos das condicionantes socioambientais e de ações empresariais. Questiona-se o papel das políticas sociais e ambientais no âmbito do licenciamento para compatibilizar proteção e empreendimento, em face de fatores que influenciam essas políticas. Para tanto, foi realizada pesquisa bibliográfica e documental. Resultados iniciais sugerem que as condicionantes do licenciamento do CLIPA funcionam mais para obtenção de legalidade e, em certa medida, de legitimidade, do que para proteção no $5^{\circ}$ Distrito.

Palavras-chave: Políticas sociais e ambientais. Grandes empreendimentos portuários. Licenciamento ambiental. Acumulação por espoliação.
Abstract: The Açu Industrial and Port Logistics Complex (CLIPA, abbreviation inn Portuguese) is located in the 5th District of São João da Barra, Rio de Janeiro State, Brazil, a territory inhabited by agricultural and fishing communities affected by the impacts of the CLIPA and targets of socio-environmental conditions and business actions. The role of social and environmental policies in the context of licensing is questioned, in order to make protection and entrepreneurship compatible, given the factors that influence these policies. To this end, bibliographic and documentary research was carried out. Initial results suggest that the licensing constraints of the CLIPA work more to obtain legality and, to a certain extent, legitimacy than the socioterritorial protection of the 5th District.

Keywords: Social and environmental policies. Large port developments. Environmental licensing. Accumulation by plundering.

Rosangela Maria Amorim Benevides-Guimarães

Bacharel em Serviço Social (Universidade Federal Fluminense), mestre em Políticas Sociais e doutoranda em Políticas Sociais no Programa de Pós-graduação em Políticas Sociais da Universidade Estadual do Norte Fluminense Darcy Ribeiro (PPGPS/UENF).E-mail: rosangbenevides@yahoo.com.br

\section{Denise Cunha Tavares Terra}

Doutora em Geografia pela Universidade Federal do Rio de Janeiro (UFRJ), mestre em Ciências Políticas pelo Instituto Universitário de Pesquisa do Rio de Janeiro (IUPERJ), graduada em Ciências Econômicas pela Universidade Candido Mendes (UCAM), professora e pesquisadora do Programa de Pós-Graduação em Políticas Sociais (PPGPS) da Universidade Estadual do Norte Fluminense Darcy Ribeiro (UENF). E-mail: deniseterra@gmail.com 


\section{Introdução}

O objetivo deste artigoép roblematizar a compatibilidade entre a proteção social e ambiental e o CLIPA. Para tal, além das proposições que fundamentam teoricamente este estudo, realizamos uma pesquisa documental recuperando informações acerca de leis e decretos, impactos, condicionantes e ações de Responsabilidade Social Corporativa (RSC). Recorremos aos Estudos de Impacto Ambiental (EIA/RIMA) e aos estudos técnicos de pesquisadores. Acessamos informações no blog do professor doutor Marcos Pedlowski, do Laboratório de Estudos do Espaço Antrópico, da Universidade Estadual do Norte Fluminense (LEEA/UENF) e no blog do professor doutor Roberto Moraes, professor aposentado do Instituto Federal Fluminense (IFF). Ainda buscamos informações nas páginas virtuais do Porto do Açu, da Prefeitura de São João da Barra (SJB) e do Instituto Estadual do Ambiente do Estado do Rio de Janeiro (INEA).

Em face dos megaportos voltados para o escoamento das commodities no Brasil e em outros países da América Latina (AL) nos anos 2000, sobretudo no Norte do estado do Rio de Janeiro (ERJ), e a reconfiguração nos territórios, faz-se necessário refletir sobre proteção social e ambiental que rebate no que denominamos de "proteção das existências sociais" nos territórios portuários. Este termo refere-se à proteção das expressões materiais e imateriais, compatíveis com modos de vida relativos aos distintos valores culturais e com a dignidade humano-social.

Por este ângulo, a proteção aqui compreendida abarca as condições objetivas e subjetivas da existência social que compõem modos de vida que devem ser protegidas dos impactos socioterritoriais dos megaportos.

\section{Licenciamento do CLIPA e uso das políticas de proteção na tentativa de "adequar interesses"}

O CLIPA possui, entre suas principais estruturas, 0 Distrito Industrial de São João da Barra (DISJB), um condomínio industrial localizado na retaguarda do Porto do Açu e voltado para a atração de empresas, e o Porto do Açu.

0 Porto do Açu se inscreve na retomada dos portos como infraestruturas necessárias para o mercado externo no ERJ que, ao se inserir na internacionalização da economia, ampliou, modernizou e construiu megaportos, conforme Monié e Vidal (2006). Possui papel relevante por fazer parte de uma rede global portuária que conecta territórios de extração e produção aos territórios do consumo, como a extração de minério de ferro em Minas Gerais e sua exportação para a China e a extração e produção de petróleo no NF e sua exportação também para a China.

De tipo porto-indústria, o Porto do Açu, pela sua escala, é intensivo em terra e água e no controle do território marítimo, por isso instalando-se em SJB, uma área com abundância desses recursos. É um empreendimento que, com base em Vainer (2007), mobiliza intensivamente o território, fragmentando-o. Fragmentação territorial, segundo Vainer (2007), é produto de três vetores que são o regionalismo, 0 localismo e os grandes projetos de investimentos (GPI). Sobre os GPIs, o autor observa que:

\begin{abstract}
Os GPIs são uma forma de organização territorial que a tudo se sobrepõe, fragmentando o território e instaurando circunscrições e distritos, que, no limite configuram verdadeiros enclaves [...] hoje, seu papel estruturador reafırma as privatização de nossos recursos e reforça tendências ao enclave e a fragmentação (VAINER, 2007, p. 12).
\end{abstract}

Desta maneira, seus impactos estão relacionados com a escala, com o consumo intensivo de recursos naturais e com a fragmentação territorial. Entre eles, destacam-se: 1) a expropriação estatal de terras dos agricultores familiares; 2) a restrição da pesca; 3) a salinização de água e solo; e 4) o agravamento da erosão costeira.

Em face desses impactos, no âmbito do licenciamento, foram adotadas condicionantes socioambientais como explicitadas nos EIA/RIMAs dos empreendimentos portuários. As condicionantes possuem base nas políticas ambientais, sociais e culturais. No entanto, observamos que elas indicam serem mais uma tentativa de "adequação de interesses" do que de proteção no $5^{\circ}$ Distrito.

Ao abordar a gestão ambiental, Quintas (2006) diz que a Política Ambiental funciona como um instrumento de busca do consenso na tentativa de criar as condições de "equilíbrio" entre desenvolvimento econômico e preservação socioambiental. Mendonça (2015) também entende, ao tratar do "licenciamento de adequação", que o papel das condicionantes é o de obtenção do consenso. 
Linha semelhante seguem Martini e Lana (2003) ao analisarem a compensação. Ela é orientada pelo princípio do poluidor-pagador, possuindo alcance restrito e enfoque econômico e utilitarista. Também possui uso político na tentativa de criar equivalência entre degradação e conservação. Sobre a mitigação, é voltada para prevenir, reduzir, atenuar e adequar os efeitos sociais e ambientais dos impactos, que são inevitáveis do ponto de vista da obra ou do empreendimento.

Sobre as políticas culturais, entendemos que também estão voltadas para a adequação ao buscarem compatibilizar racionalidades e valores distintos, geralmente opostos entre si.

Sobre as políticas sociais, com base em Pereira (2013) e Pastorini (2006), funcionam para compensar danos e, ao mesmo tempo, como garantidoras de direitos de cidadania, assegurando a reprodução do modelo de desenvolvimento capitalista. Revelam que a proteção social perpassa a satisfação das necessidades humanas, porém dentro dos limites impostos pelo capital financeirizado, no caso do CLIPA, como mecanismos de adequação.

Acresce-se a esse cenário das políticas protetivas 0 desmonte institucional iniciado por governos federais na década de 1990, acentuado a partir de 2016 e, sobretudo, em 2019, ilustrado pela expressão do ministro do Meio Ambiente sobre passar a "boiada"1.

Além do uso instrumental e do desmonte das políticas protetivas, fatores mais específicos associados ao CLIPA também interferem na "proteção das existências sociais" no $5^{\circ}$ Distrito. São as condicionantes do licenciamento, as ações de RSC e as relações público-privadas.

Quanto ao termo "proteção das existências sociais", este refere-se à proteção das expressões materiais e imateriais, compatíveis com modos de vida relativos aos distintos valores culturais, como de pescadores artesanais e de agricultores familiares afetados pelos impactos do CLIPA, no $5^{\circ}$ Distrito, e com a dignidade humano-social, abrangendo as condições objetivas e subjetivas da existência social que compõem modos de vida.

\section{Impactos, condicionantes e as ações de RSC versus proteção socioterritorial}

Postulamos que, no plano legal e político-institucional, o licenciamento é adotado para fins de controle dos impactos visando à proteção socioambiental, enquanto, para os empreendedores, é um instrumento de legalização e de credibilidade do empreendimento junto a credores (como instituições financeiras), fornecedores e clientes e sociedade, como pode ser observado no portfólio do Porto do Açu que informa ser um empreendimento licenciado, i.e., legalizado.

No licenciamento do CLIPA, pesquisas, como a de Latini (2016), analisam e apontam para a fragmentação das estruturas operacionais do CLIPA, a falta de informação e a ausência de transparência do licenciamento, entre outras. Quanto às condicionantes, são instrumentalizadas pelo empreendimento e, juntamente com as ações de RSC - algumas delas confundindo-se com as condicionantes - sugerem ser usadas para fins de marketing empresarial, como é o caso do reassentamento e do Programa de Fortalecimento Familiar (conf. informação veiculada pelo Porto do Açu on-line), direcionados para os agricultores familiares desapropriados, conforme Quadro 1:

\footnotetext{
1 Expressão utilizada pelo ministro do Meio Ambiente Ricardo Salles, em reunião ministerial no dia 22 de abril de 2020, em período de pandemia da Covid-19, referindo-se à oportunidade de mudar as regras ambientais e simplificar normas, no sentido de afrouxar as medidas protetivas ambientais do governo federal.
}

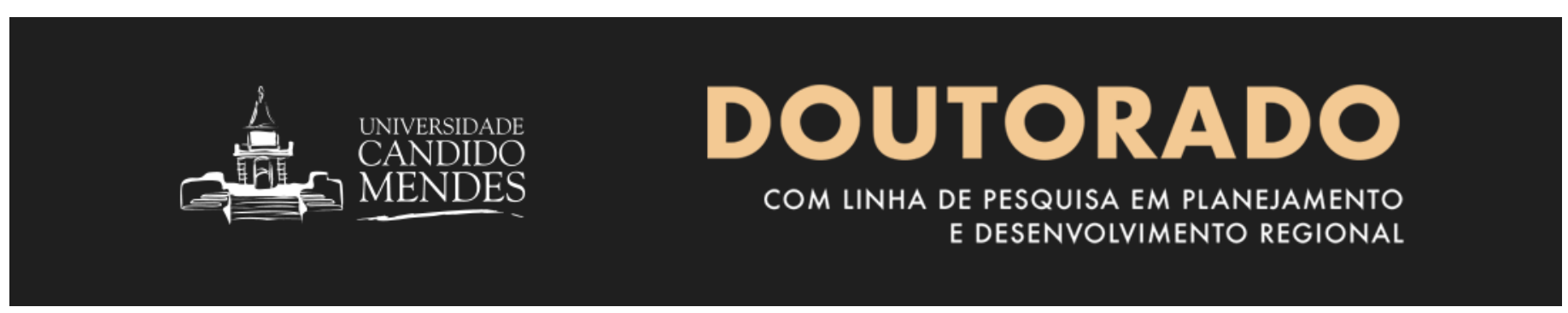


Quadro 1: Desapropriação de terras, condicionantes e RSC

\begin{tabular}{|c|c|c|}
\hline Efeitos relacionados & Condicionantes & $\mathrm{RSC}$ \\
\hline $\begin{array}{l}\text { Rompimento de relações } \\
\text { de vizinhança e } \\
\text { comunitária; } \\
\text { Desestruturação das } \\
\text { relações simbólicas com o } \\
\text { lugar; } \\
\text { Desestabilização da } \\
\text { estrutura agrária local } \\
\text { pela mudança dos padrões } \\
\text { de apropriação da terra; } \\
\text { Interrupção de práticas } \\
\text { locais de produção e de } \\
\text { subsistência; no } \\
\text { Interferências } \\
\text { desenvolvimento agrícola } \\
\text { local. }\end{array}$ & $\begin{array}{l}\text { Programa de } \\
\text { Comunicação Social e } \\
\text { Divulgação; } \\
\text { Programa de } \\
\text { Desapropriação e } \\
\text { relocação da população } \\
\text { ocupante das terras; } \\
\text { Assentamento Vila da } \\
\text { Terra; } \\
\text { Indenização; } \\
\text { Programa de } \\
\text { Fortalecimento da } \\
\text { Agricultura Familiar; } \\
\text { Programa de } \\
\text { Mobilização, Captação e } \\
\text { Desmobilização da mão } \\
\text { de obra. }\end{array}$ & $\begin{array}{l}\text { Programa de Fortalecimento } \\
\text { da Agricultura Familiar; } \\
\text { Doação de instrumentos de } \\
\text { trabalho para associação de } \\
\text { produtores rurais; } \\
\text { Doação de } 1 \text { ônibus e } 1 \\
\text { caminhão para a Secretaria } \\
\text { de Agricultura de São João } \\
\text { da Barra; } \\
\text { Projeto Feira do Porto de } \\
\text { comercialização de produtos } \\
\text { agrícolas. }\end{array}$ \\
\hline
\end{tabular}

Fonte: Elaboração própria a partir de informações do RIMA/DISJB e Porto do Açu (on-line)

Entre as condicionantes, o reassentamento Vila da Terra, dividido em lotes de 2 ha e com casas padronizadas, visou a atender moradores que tinham até 10 ha de terras. Entre as queixas dos reassentados, a principal, conforme pesquisa de Alvarenga (2013), era quanto ao não recebimento do título de propriedade dos lotes devido à Fazenda Palacete, onde foi construído o reassentamento, estar em litígio. Outra questão destacada por Alvarenga (2013, p. 82) foi o receio dos reassentados de perderem o benefício social Auxílio Produção, concedido pela empresa LLX caso esta soubesse das críticas e queixas, que, para o pesquisador, "representa perda de autonomia e uma forma de intimidação".

A indenização foi direcionada para as famílias com terrenos maiores de 10 ha, com aproximadamente $80 \%$ das famílias ainda aguardando o recebimento. Elas contestam legitimamente em juízo o valor calculado pelos peritos da Companhia de Desenvolvimento Industrial do Estado do Rio de Janeiro (CODIN), que ficou abaixo dos valores estimados pelos peritos indicados pela justiça de SJB. Destaca-se também que 90\% dos processos de desapropriação distribuídos no final de 2010 na Comarca de São João da Barra - que têm como autora a CODIN - afetaram pessoas idosas, e alguns proprietários faleceram sem terem recebido a compensação, passados dez anos das primeiras desapropriações. Além disso, a terra expropriada está sem cumprir sua função social, com aproximadamente $90 \%$ sem uso.
Necessário assinalar que as desapropriações ocorreram por meio de violência, violação de direitos, assédio moral, intimidações e que essas duas condicionantes estão longe de compensar a violência sofrida pelos agricultores expropriados. Eles tiveram, utilizando a expressão de Bermann (2007, p. 142), "violentadas as suas bases materiais e culturais de existência", e as condicionantes não dão respostas a essa violência. 0 reassentamento não assegura as condições de vida anteriores, e as indenizações - judicialmente contestadas - revelam que a terra foi expropriada para fins de especulação. Dessa maneira, essas condicionantes não protegem as existências sociais dos expropriados do Açu, antes indicando seu uso para fins de marketing e legalidade do CLIPA.

Sobre as ações de RSC, entendemos que a tomada da terra e da moradia e a perda dos instrumentos de trabalho mostraram-se passíveis de compensação pelo empreendimento, mesmo não sendo realizadas na perspectiva de "proteger as existências sociais" dos agricultores. Por sua vez, o rompimento de vínculos e a desorganização familiar e comunitária e as perdas simbólicas são listados como efeitos relacionados com a desapropriação e remoção, porém não são apreendidos como objetos de mitigação ou de compensação e nem de RSC, indicando que, no licenciamento, só é mitigado e compensado o que é precificado pelo mercado. 
No caso do controle dos impactos sobre a pesca, este também é feito com medidas que incluem condicio-

nantes e ações de RSC, conforme Quadro 2:

\section{Quadro 2: Impactos na pesca, condicionantes e RSC}

\begin{tabular}{|c|c|c|}
\hline Efeitos relacionados & Condicionantes & $\mathrm{RSC}$ \\
\hline $\begin{array}{l}\text { Perda ou restrição de } \\
\text { área da pesca; } \\
\text { Risco de acidentes } \\
\text { com embarcações; } \\
\text { Perda de materiais e } \\
\text { instrumentos de } \\
\text { trabalho }\end{array}$ & $\begin{array}{l}\text { Programa de Comunicação } \\
\text { Social e Divulgação; } \\
\text { Programa de } \\
\text { Ambiental; } \\
\text { Programa de } \\
\text { Ambienão } \\
\text { Trabalhadoração } \\
\end{array}$ & $\begin{array}{l}\text { Reforma e doação de equipamentos } \\
\text { odontológicos; } \\
\text { Reforma e doação de equipamentos } \\
\text { e treinamento de monitores de } \\
\text { informática; } \\
\text { Legalização de embarcações; } \\
\text { Reforma da sede do Núcleo de } \\
\text { Pesca do Açu; } \\
\text { Doação de kits de navegação; } \\
\text { Doação de lancha e computador; } \\
\text { Implantação de Centro de } \\
\text { Formação de Pescadores; } \\
\text { Aquisção de imóvel para Colônia } \\
\text { de pescadores; } \\
\text { Cursos, oficinas e treinamentos }\end{array}$ \\
\hline
\end{tabular}

Fonte: Elaboração própria a partir de informações do RIMA/DISJB e Porto do Açu (on-line)

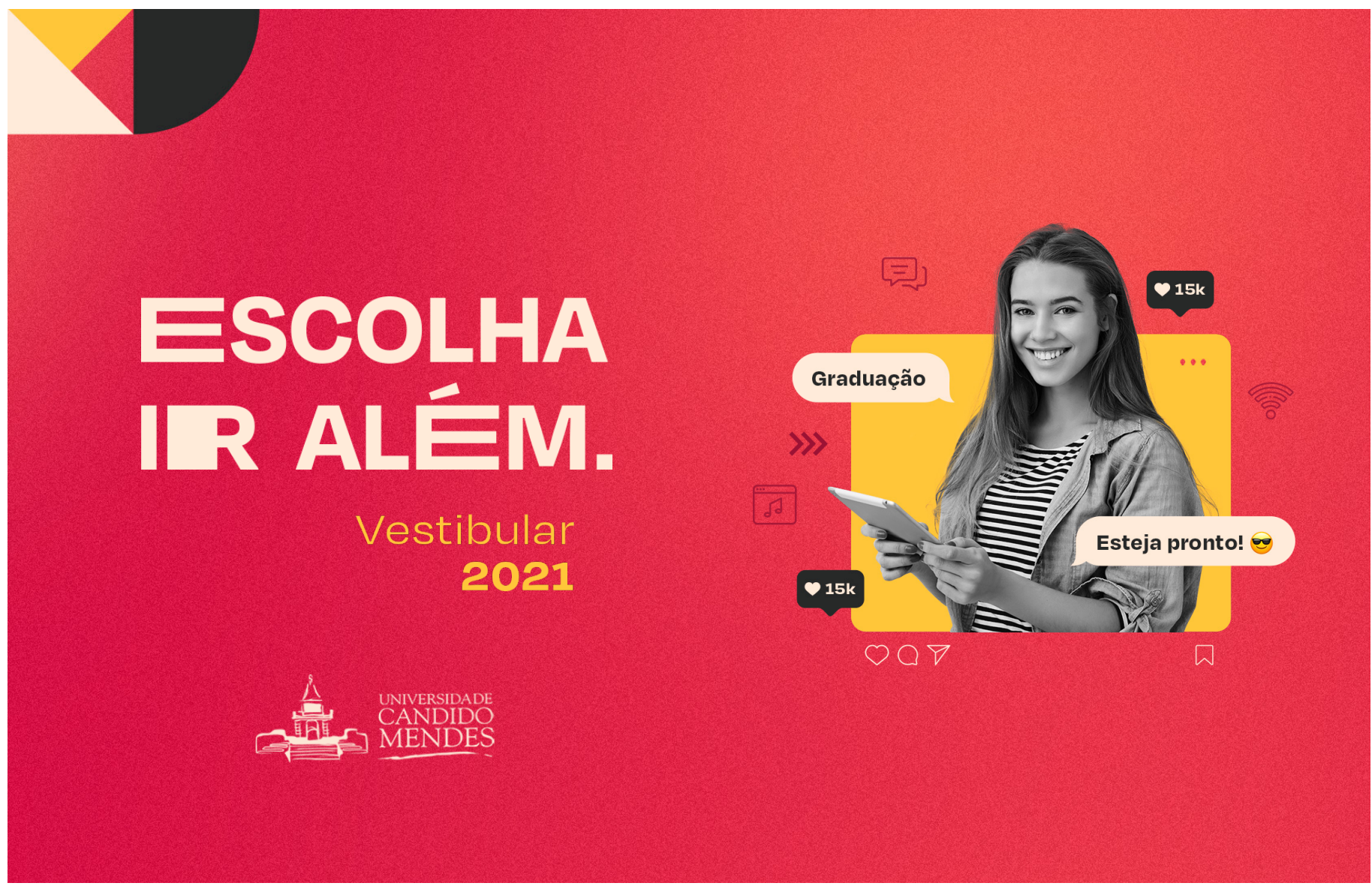


0 Quadro 2 mostra que a Educação Ambiental (EA) juntamente com as doações para as Colônias (Z-01, Z-02, Z-19) são as principais medidas de controle dos impactos na pesca. Esse dado é relevante não só pelas concepções que orientam a EA como pelo seu papel no licenciamento quanto à "proteção das existências sociais".

Em uma perspectiva conservadora, a EA é um instrumento disciplinador do público-alvo, que, no caso do CLIPA, são os pescadores a serem orientados para a nova realidade da pesca, agora restrita, e os trabalhadores da segurança, geralmente terceirizados, para lidarem com os pescadores que resistem à interdição, evitando acidentes e perda de material de trabalho.

A concepção crítica da EA, por sua vez, vincula-se às lutas contra a injustiça ambiental e à superação das relações sociais destrutivas da natureza. Ela busca, por meio de um processo argumentativo contínuo, ressignificar ideologicamente a questão ambiental ao articular EA crítica, justiça ambiental e ecologia política (LOUREIRO e LAYRARGUES, 2013).

Nessa concepção se vincula o Projeto Pescarte, um projeto de mitigação socioambiental da Petrobras desenvolvido em parceria com a UENF em SJB e em outros municípios do Norte Fluminense e Baixadas Litorâneas.

Contudo, a despeito da importância da EA como condicionante, ela não é uma panaceia e não possui capacidade para responder às questões objetivas e subjetivas que envolvem o controle da pesca pelo Porto do Açu, que afeta, além da renda e o trabalho, a autonomia e a liberdade, "expressões da existência social do pescador".

Mostra-se curioso a EA ser uma condicionante adotada na maioria dos licenciamentos que envolvem grandes empreendimentos como o CLIPA, e ainda a forma como é adotada. 0 empreendimento impacta, e os impactados tornam-se os alvos da EA; o gerenciamento da EA fica a cargo dos empreendimentos - assim como ocorre com as demais condicionantes - que possuem a obrigação de comunicar, via relatórios ao órgão licenciador, o desenvolvimento da condicionante.

Sobre as ações de RSC, elas ocorrem em forma de doações de equipamentos, instrumentos de trabalho, reforma de infraestrutura e outras para as colônias. Elas sugerem que o Porto do Açu busca compensar o impacto na pesca com as mesmas atividades que a restringem. Também podem funcionar como apaziguamento de conflitos e silenciamento de protestos, não se voltando para a proteção dessa atividade tradicional. As doações também podem criar conflitos entre os pescadores cooptados e os que se negam a se comprometer com o empreendimento.

Quanto ao impacto da salinização de água e solo, este ocorreu a partir de 2012 e afetou a agricultura, a irrigação, dessedentação de animais e consumo humano. No entanto, mesmo comprovado por estudos científicos realizados pela UENF², e com sua previsão no RIMA/DISJB, a empresa LLX negou sua ocorrência (LATINI, 2016). Diante dessa posição da LLX, agricultores e o Ministério Público Federal ajuizaram ação, e a LLX foi multada, obrigada a apoiar financeiramente a implantação do Parque Estadual do Açu e a reparar os pontos dos canais do $5^{\circ}$ Distrito que estavam assoreados.

0 agravamento da erosão costeira ocorreu a partir de 2012 devido à construção do quebra-mar do Porto do Açu. Em 2014, a erosão provocou a interdição de casas e de pequenos comércios pela Defesa Civil de $\mathrm{SJB}$, e houve comprometimento da infraestrutura local, no entanto, com base em um estudo encomendado pela Prumo, atual controladora do CLIPA - que concluiu que o efeito erosivo não tinha relação com as estruturas portuárias - a empresa não reconheceu o impacto como relacionado com o Porto do Açu, apesar de constar a sua previsão no RIMA da Unidade de Construção Naval (UCN) e sua respectiva condicionante, o Programa de Monitoramento da Dinâmica Sedimentológica Marinha e de Erosões Costeiras (PEDLOWSKI, 2014).

\section{Relações público-privadas: influência na "proteção das existências sociais" no Açu}

No âmbito das relações entre o empresário Eike Batista - do grupo EBX e primeiro proprietário do CLIPA - e empresas do Porto com governos municipais, estaduais e federal, e com políticos, estão legislações, apoios a candidaturas, corrupção, parcerias em obras e doações.

$2 \quad$ Em 2012, foi realizada coleta de água em vários pontos do $5^{0}$ Distrito por pesquisadores do Laboratório de Ciências Sociais da UENF. Entre os meses de abril e agosto de 2015, para sua pesquisa de mestrado, Latini coletou 110 amostras de água. 
Pelo município de SJB, destacam-se a Lei n. ${ }^{0}$ 50/2006, que aprovou o novo Plano Diretor definindo as zonas industriais de SJB, e a Lei $n .{ }^{0}$ 105/2008, que disciplina tratamento fiscal de imóveis e serviços vinculados à construção da Zona Industrial do Porto do Açu.

Pelo ERJ, estão os decretos que desapropriaram 7.200 ha de terras no âmbito da parceria entre a empresa LLX/EBX e a CODIN para a construção do DISJB. Essa parceria, que resultou na venda das terras pela CODIN para a LLX sem licitação, é questionada judicialmente ${ }^{3}$.

Em SJB, a reeleição da prefeita Carla Machado ${ }^{4}$ e, em Campos dos Goytacazes, a eleição de Rosinha Garotinho ${ }^{5}$ à prefeitura - municípios de influência direta do CLIPA - contaram com o apoio de Eike Batista, que, em 2011, recebeu a medalha de Barão de São João da Barra, maior honraria do município.

O CLIPA também teve apoio do Legislativo de SJB. Recebeu apoio de presidentes da República, como de Dilma Rousseff, em visita em 2012, e de Michel Temer, em 2017, que, na ocasião, assinou o decreto de criação da Zona de Processamento de Exportação (ZPE), e o apoio da grande mídia e de organizações empresariais. À luz dos novos regionalismos e localismos (VAINER, 2007), essas relações são reveladoras das imbricações entre forças políticas locais e regionais e forças externas que se entrecruzam para garantir os interesses de grandes corporações e empreendimentos, como do grupo EBX e do CLIPA, por meio de vantagens fiscais e ambientais.

Sob a ótica da "acumulação por espoliação" (HARVEY, 2010) ${ }^{6}$, essas relações público-privadas revelam a subserviência e captura de governos e políticos que se curvam ao mercado e às grandes corporações, que possuem interesses alheios às expectativas locais/ regionais. É nítido que o que está ocorrendo no $5^{\circ}$ Distrito também expressa a omissão de governantes municipais e estaduais em face dos danos à "proteção das existências sociais".

3 Ação Civil Pública n. ${ }^{\circ}$ 0331355-25.2015.8.19.0001, do Tribunal de Justiça do ERJ.

$4 \quad$ Prefeita no período de 2005 a 2008 e de 2017 a 2020.

5 Governadora do estado do Rio de Janeiro no período de 2003 a 2007 e prefeita de Campos dos Goytacazes entre 2009 e 2012 e de 2013 a 2016.

6 Em Harvey a espoliação atual remete às origens da apropriação na fase da acumulação primitiva de capital, realizada com métodos de pilhagem, saque, escravização, violência e espoliação, para fins de valorização do capital superacumulado, que através dos métodos espoliativos libera recursos (trabalho, terra, água, minerais e outros) a preço baixo.
Essas relações também mostram os vínculos que grandes empreendimentos com perfil espoliador têm com a corrupção. É o caso do ex-governador do ERJ Sérgio Cabral - preso desde 2016 pela Operação Lava Jato do Ministério Público Federal - que, em 2019, confessou ter recebido 16 milhões de dólares para sancionar, em 2009, decretos de desapropriação para o DISJB, favorecendo o Grupo EBX, conforme reportagem de Mesquita (2019) para o Jornal Brasil de Fato.

Com base em Gudynas (2017), ao alimentar partidos políticos e práticas eleitorais, a corrupção facilita a ocultação de impactos sociais e ambientais, a violência e criminalização das comunidades locais e a obtenção de concessões e de vantagens tributárias, e muito provavelmente, sem ela, projetos com características de alto impacto dificilmente seriam aprovados.

Além das condicionantes do CLIPA, o estado se faz presente em SJB com as rendas petrolíferas (royalties e participações especiais) e com o Programa Bolsa Família (PBF) que, em maio de 2018, tinha 3.274 famílias beneficiárias (MDS, 2018), quase 10\% da população do município, que é de, aproximadamente, 35 mil habitantes. $05^{\circ}$ Distrito é alvo do projeto PEA Pescarte, citado anteriormente, e conta com instituições de assistência social (Centro de Referência da Assistência Social), saúde (Unidade Básica de Saúde) e unidades escolares. Essas informações sociais são importantes para pensar o papel das instituições protetivas no $5^{\circ}$ Distrito.

$05^{0}$ Distrito e outras localidades de SJB também recebem apoio das empresas portuárias, conforme Quadro 3: 
Quadro 3: Obras, apoios e doações do Porto do Açu em SJB

\begin{tabular}{|c|c|c|c|c|}
\hline Infraestrutura & $\begin{array}{l}\text { Administração } \\
\text { pública }\end{array}$ & Saúde & $\begin{array}{l}\text { Segurança } \\
\text { pública }\end{array}$ & Cultura - Apoio \\
\hline $\begin{array}{ll}\text { Construção } & \text { de } \\
\text { linha } & \text { de } \\
\text { transmissão } & \text { de } \\
\text { energia } & \\
\text { elétrica } & \\
\end{array}$ & $\begin{array}{l}\text { Apoio técnico } \\
\text { para } \\
\text { elaboração do } \\
\text { Plano Diretor }\end{array}$ & $\begin{array}{ll}\text { Reforma } & \text { do } \\
\text { Posto } & \text { de } \\
\text { urgência } & \text { do } \\
\text { Açu } & \end{array}$ & $\begin{array}{l}\text { Doação de } \\
\text { ônibus } \\
\text { equipamento } \\
\text { s }\end{array}$ & $\begin{array}{l}\text { Agremiações } \\
\text { carnavalescas }\end{array}$ \\
\hline $\begin{array}{l}\text { Obras } \\
\text { asfálticas }\end{array}$ & $\begin{array}{lr}\text { Construção } & \text { das } \\
\text { fundações } & \text { do } \\
\text { novo prédio do } \\
\text { Fórum }\end{array}$ & & 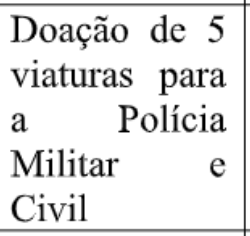 & Festa de pescadores \\
\hline $\begin{array}{l}\text { Dragagem de } \\
\text { canal }\end{array}$ & & & & Projeto teatral \\
\hline $\begin{array}{l}\text { Pavimentação } \\
\text { de estradas }\end{array}$ & & & & Projeto de capoeira \\
\hline \multirow[t]{2}{*}{$\begin{array}{lr}\text { Instalação } & \text { de } \\
\text { poços } & \\
\text { artesianos } & \text { e } \\
\text { sistemas } & \text { de } \\
\text { distribuição } & \\
\end{array}$} & & & & $\begin{array}{l}\text { Certificação do } \\
\text { Patrimônio Cultural } \\
\text { e Centro de } \\
\text { Desenvolvimento } \\
\text { Territorial }\end{array}$ \\
\hline & & & & $\begin{array}{l}\text { Concurso } \\
\text { marchinhas }\end{array}$ \\
\hline
\end{tabular}

Fonte: Elaboração própria a partir de informações do RIMA/DISJB e Porto do Açu (on-line)

As informações do Quadro 3 referem-se a obras, apoios e doações feitas para áreas públicas, como de infraestrutura, planejamento territorial, judiciário, saúde, segurança pública e cultura. São áreas estratégicas no quesito capilaridade e controle territorial corporativo e mais ainda para a proteção social e ambiental no território.

Essas informações também são reveladoras da redução do estado na oferta de serviços públicos no território e da abrangência da RSC. Por requisitarem responsabilidades além das tradicionais (fornecedoras de bens e serviços), Schroeder e Schroeder (2004, p. 6) dizem que as empresas estão "afirmando-se como propagadora e garantidora do bem-comum". No caso de SJB e do seu $5^{\circ}$ Distrito, as informações do Quadro 3 sugerem que as empresas portuárias estão, se não atribuindo para si esse papel de "garantidoras do bem-comum", buscam capilaridade e controle territorial.

Misoczky e Böhm (2013), ao pesquisarem sobre a RSC em território minerário na Argentina, identificaram que seus projetos e ações são focados no risco social, junto com os riscos tradicionais do negócio. São destinados a aumentar o capital humano, social e cultural por meio de parcerias com prefeituras e de doações que são acompanhadas obrigatoriamente pelo reconhecimento público em favor da empresa, que é o que essas informações sugerem que esteja ocorrendo no $5^{\circ}$ Distrito, se estendendo para todo o município.

Misoczky e Böhm (2013, p. 328 e 330) também observaram que as empresas buscam "estabelecer vínculos institucionais com as universidades públicas e privadas por meio de contratos e subsídios", e que a RSC é "um instrumento de desmobilização das resistências, de silenciamento de contestações históricas, ao invés de lidar com questões (sociais, econômicas e ambientais) decorrentes das atividades da empresa".

O cenário indica que o controle dos riscos aos negócios do CLIPA não contempla os riscos à "proteção das existências sociais" em SJB, seja por parte das empresas, seja pelo governo municipal. Assim, diante do exposto, cabe também considerar o papel das universidades locais/regionais na proteção socioterritorial do $5^{\circ}$ Distrito. 


\section{Conclusão}

Este estudo tratou da compatibilidade entre a "proteção das existências sociais" e o CLIPA, identificando a falta de correspondência entre proteção e o megaporto, devido aos seguintes fatores que reverberam nas respostas das políticas protetivas: 1) a instrumentalização do licenciamento pelo CLIPA; 2) as ações de RSC voltadas ao controle do risco; e 3) as relações público-privadas.

Isto se coloca tendo em vista que, mesmo com as condicionantes implementadas, os grupos sociais afetados, como os agricultores familiares expropriados de suas terras, ainda aguardam serem compensados da forma que consideram justa, e os pescadores artesanais continuam aguardando respostas à exclusão dos "campos de pesca".

Além do mais, há efeitos dos impactos que não foram objeto de mitigação ou compensação. São aqueles relativos aos valores culturais e simbólicos de grupos sociais tradicionais como o dos pescadores artesanais e de grupos sociais como o dos agricultores familiares, que, de forma semelhante aos pescadores, possuem modos autossustentáveis de vida e trabalho, e de reprodução social, mediados pelos recursos naturais e pela organização social em torno dos vínculos familiares e comunitários e que têm no território o seu lugar de pertencimento.
Outros impactos, como a salinização de água e solo e o agravamento da erosão costeira, tiveram sua relação com o empreendimento negada pelo empreendedor, o que inviabilizou qualquer forma de compensação e mitigação, a não ser pela via da judicialização, como ocorreu com a salinização. Por fim, as relações público-privadas são óbices à garantia de proteção dos afetados, ao mesmo tempo em que viabilizaram o empreendimento, enquanto as ações de RSC se voltam para o controle do risco no território. Desta maneira, o licenciamento e suas condicionantes indicam não serem suficientes para dar respostas aos efeitos dos impactos e garantir a "proteção das existências sociais" no $5^{\circ}$ Distrito, mas garantir a legalidade e funcionarem como ferramentas de marketing do empreendimento junto às instituições financeiras, fornecedores e clientes.

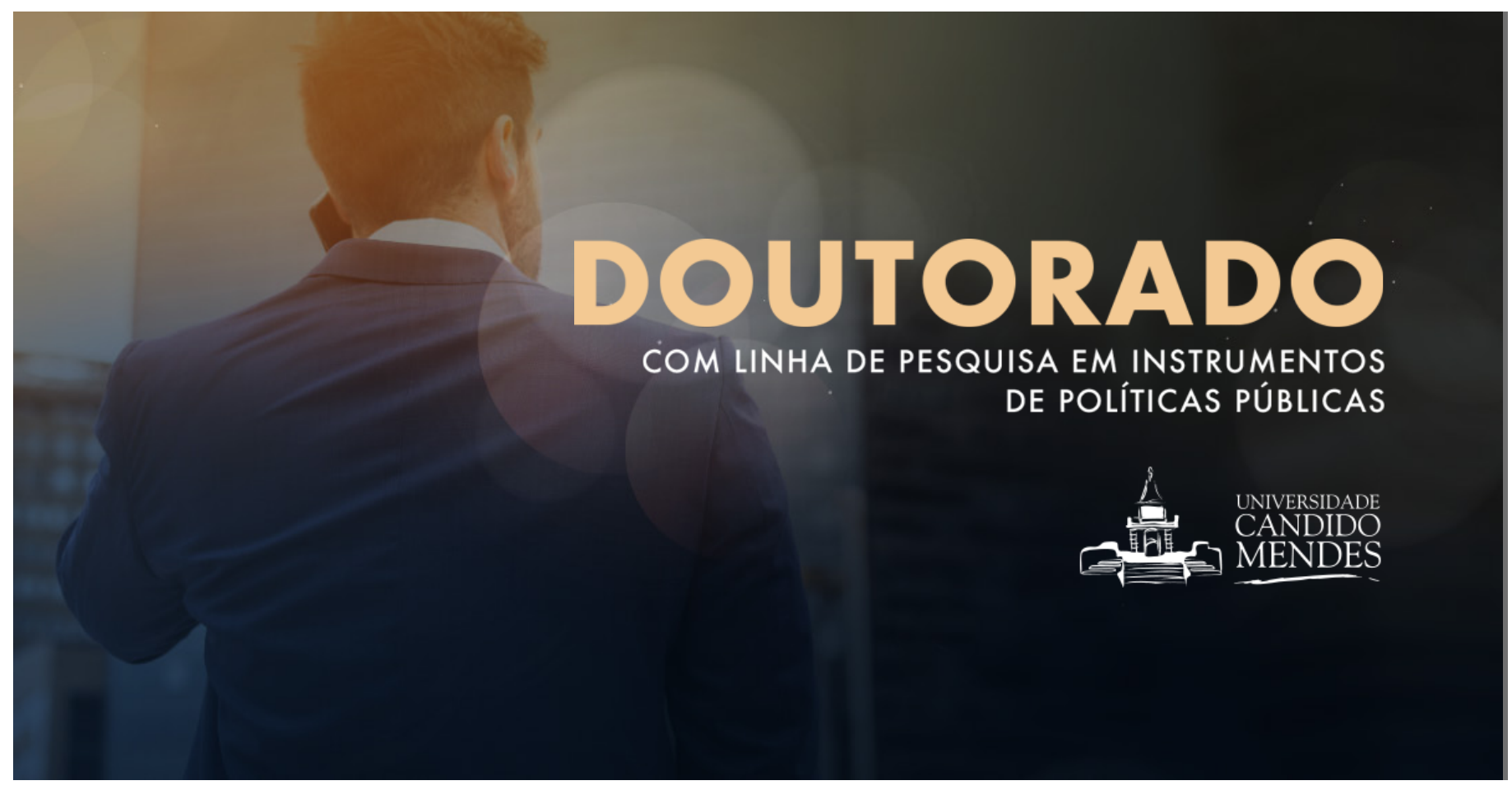




\section{Referências}

ALVARENGA, Felipe M. Os deserdados do desenvolvimento: o caso da implantação do complexo portuário e industrial do Açu e seus impactos socioterritoriais. 2013. Dissertação. (Mestrado em Políticas Sociais) - Universidade Estadual do Norte Fluminense Darcy Ribeiro, Campos dos Goytacazes, 2013.

BERMANN, Célio. Impasses e controvérsias da eletricidade. Estudos Avançados, São Paulo, v. 21, n. 59, 2007.

GUDYNAS, Eduardo. Corrupción y Extractivismo: mutuamente asociados. Revista IUH on-line, São Leopoldo, 10 fev. 2017. Disponível em: http://www. ihu.unisinos.br/161-noticias/noticias-espanol/564622-corrupcion-y-extractivismo-mutuamente-asociados" http://www.ihu.unisinos.br/161-noticias/ noticias-espanol/564622-corrupcion-y-extractivismo-mutuamente-asociados. Acesso em: 10 nov. 2019.

HARVEY, David. 0 Novo Imperialismo. São Paulo: Edições Loyola, 2010.

LATINI, Juliana R. A Avaliação de Impacto Ambiental (AIA) enquanto instrumento participativo e preventivo no contexto do neodesenvolvimentismo: 0 caso do Complexo Logístico Industrial do Porto do Açu (CLIPA). 2016. Dissertação. (Mestrado em Ecologia e Recursos Naturais) - Universidade Estadual do Norte Fluminense Darcy Ribeiro, Campos dos Goytacazes, 2016.

LOUREIRO, Carlo F. B; LAYRARGUES, Philippe P. Ecologia Política, Justiça e Educação Ambiental Crítica: perspectivas de aliança contra-hegemônica. Trab. Educ. Saúde, Rio de Janeiro, v. 11, n. 1, p. 53-71, jan./abr., 2013.

MARTINI, Luiz C. P.; LANNA, Antônio E. Medidas compensatórias aplicáveis à questão da poluição hídrica de origem agrícola. RBRH - Revista Brasileira de Recursos Hídricos [online], v. 8, n. 1, p. 11-136, jan./mar., 2003. Disponível em: https://abrh.s3.sa-east-1.amazonaws.com/ Sumarios/37/9b7720ca39629f937d3d08f9ce0fa04f_b146d63112b441abd81848eefdedee87.pdf. Acesso em: 20 out. 2019.

MDS - Ministério do Desenvolvimento Social e Combate à Fome. Relatório de Informações Sociais do BF/Cadastro Único. Maio 2018. Disponível em: http://mds.gov.br/sistemas/sistemas-1/. Acesso em: 13 jul. 2018.

MENDONÇA, Gilberto M. de. 0 Brasil licenciando e andando: as relações da política pública ambiental brasileira com a produção e a expansão capitalista do território. 2015. Tese (Doutorado em Políticas Públicas, Estratégias e Desenvolvimento) - Instituto de Economia, Universidade Federal do Rio de Janeiro, Rio de Janeiro, 2015.

MESQUITA, Clívia. Cabral confessa propina de Eike para desapropriar terras e construir o Porto do Açu. Brasil de Fato, Rio de Janeiro, 28 fev. 2019. Disponível em https://www.brasildefatorj.com.br/2019/02/28/sergio-cabral-confessa-propina-de-eike-batista-para-construir-porto-do-acu-rj" https:// www.brasildefatorj.com.br/2019/02/28/sergio-cabral-confessa-propina-de-eike-batista-para-construir-porto-do-acu-rj. Acesso em: 16 jun. 2020.

MISOCZKY, Maria C.; BÖHM, Steffen. Resistindo ao desenvolvimento neocolonial: a luta do povo de Andalgalá contra projetos megamineiros. Cad. EBAPE.BR [online], v. 11, n. 2, p. 311-339, jun. 2013. Disponível em: http://bibliotecadigital.fgv.br/ojs/index.php/cadernosebape/article/ view/9222/8320. Acesso em: 20 nov. 2019.

MONIÉ, Frédéric; VIDAL, Soraia M. do S. C. Cidades, portos e cidades portuárias na era da integração produtiva. RAP [online], v. 40, n. 6, p. 975-995, nov./dez., 2006. Disponível em: https://www.scielo.br/pdf/rap/v40n6/03.pdf. Acesso em: 10 out. 2019.

PASTORINI, Alejandra. As políticas sociais e o serviço social: instrumento de reversão ou manutenção das desigualdades? In: MONTAÑO, Carlos. A natureza do serviço social: um ensaio sobre sua gênese, a especificidade e sua reprodução. São Paulo: Cortez, 2006.

PEDLOWSKI, Marcos A. Relatório Técnico sobre a análise da variação da linha de costa na Praia do Açu. Laboratório de Estudos do Espaço Antrópico (LEEA). Centro de Ciências do Homem (CCH). Universidade Estadual do Norte Fluminense (UENF). Campos dos Goytacazes, set., 2014 Disponível em: http://www.robertomoraes.com.br/2014/09/analises-sobre-alteracoes-na-linha-da.html Acesso em: 04 jul. 2020.

PEREIRA, Potyara A. P. Proteção Social contemporânea: cui prodest? Serv. Soc. Soc., São Paulo, n. 116, p. 636-651, out./dez., 2013.

PORTO DO AÇU. Disponível em: https://portodoacu.com.br/sustentabilidade/gestao-social/. Acesso em: 13 out. 2020.

QUINTAS, José S. Introdução à gestão ambiental pública. 2 ed. revista. Brasília: IBAMA, 2006.

SCHROEDER, Jocimari T.; SCHROEDER, Ivanir. Responsabilidade Social Corporativa: limites e possibilidades. RAE [online], v. 3, n. 1, p. 1-10, jan./jun., 2004. Disponível em: http://www.rae.com.br/eletronica/index.cfm?FuseAction=Artigo\&ID=1573\&Secao=COMPTO\&Volume=3\&Numero=1\&Ano=2004. Acesso em: 20 set. 2019.

VAINER, Carlos. Planejamento territorial e projeto nacional: os desafios da fragmentação. R. B. Estudos Urbanos e Regionais [online], v. 9, n. 1, p. 9-23, 2007. Disponível em: https://rbeur.anpur.org.br/rbeur/article/view/167/151. Acesso em: 10 out. 2019. 